\title{
The beginnings of solar-terrestrial studies
}

\section{from David W. Hughes}

THE early years of the nineteenth century mark a watershed in astronomy. From that time astronomers ceased to concentrate on recording the positions and movement of celestial objects and astrophysics began its growth into the dominant force it is today. As documented in a recent review of the birth of the study of solar-terrestrial relations (Vistas Astr. 25, 419; 1982), a factor that helped this transformation was the realization, as a result of geomagnetic, auroral and meteorological observations, that there was an obvious nongravitational interaction between the Sun and the Earth.

Our knowledge of the existence of sunspots is centuries old but the periodicity of their occurrence, the so-called solar cycle, was only reported as recently as 1843. H. Schwabe, a one-time apothecary of Dessau, devoted himself to the observation and recording of sunspots (some say partly in the hope of discovering an intra-Mercurial planet). By 1838 he began to suspect that the 'spottiness' of the Sun changed with a period of about 10 years. He published his conclusions in Astronomische Nachrichten (20, no. 495) but his discovery did not become widely known until Baron von Humboldt publicized it in 1851 in the third volume of his popular work Cosmos. This popularization opened the flood gates.

Colonel Sabine of the British army had been analysing a series of magnetic field measurements taken from a group of observatories dotted throughout the British colonies. They showed that the Earth's field underwent small fluctuations, the amplitudes of which varied with time. As Sabine wrote: "It happens by a most curious coincidence" that the magnitude and frequency of magnetic disturbances, on a global scale, had a maximum in 1848 and a minimum in 1843 , following the sunspots. Sabine published his findings in March 1852 and A. Gautier and Rudolf Wolf independently came to the same conclusions and published in the same year.

\section{As far back as 1747, Hiorter queried}

"Who could have thought that the northern lights would have a connection and a sympathy with the magnet, and that these northern lights, when they draw southwards across our zenith or descend unequally towards the eastern and western horizons could, within a few minutes, cause considerable oscillations of the magnetic needle through whole degrees?'”

Suggestıons of a close link between solar cycle and the frequency of aurorae were quickly made in the 1850 s but, unfortunately, the scarcity of records made

David W. Hughes is a lecturer in Astronomy and Physics at the University of Sheffield, Sheffield S3 $7 R H$. the periodicity of the auroral occurrence frequency difficult to establish.

Speculation about a connection between spots and aurorae and spots and the weather had been made in the mideighteenth century. In 1801, William Herschel wen so far as to try and find a correlation between the number of spots and the price of corn, the latter obviously being influenced by the amount of fine weather. The 1850 s was a time when all regularly observed meteorological variables were analysed for periodicities. The British with their colonial interests were especially involved and Indian weather reports were carefully perused with the hope of producing reliable longrange weather predictions.

The relationship between solar cycles and variations in magnetic activity was confirmed when scientists realized that predictions of magnetic disturbances made by using sunspot observation were reasonably good. Astrophysical mechanisms connecting changes on the Sun and the consequent particle and radiation flux to aurorae and magnetic disturbances on Earth were also speedily established. The importance of the solar cycle was recognized and John Herschel's question "What can there be to determine a periodicity of this kind in the Sun?" became, and still remains, an important stimulus to astrophysicists.

Sun-weather relationships were a different matter. Post hoc correlations might be detected but predictions from them lacked accuracy. There were also far too many weather parameters to choose from. Even today, though many causal relationships have been suggested between ground temperature, rainfall, pressure and storms and sunspot activity, none has been generally accepted.
Air pollution in the A and deposition in the Arctic has recently been begun by the Norwegian Institute for Air Research with the support of British Petroleum Ltd. Not only is the Arctic an important region climatologically, but the increasing interest in the exploitation of Arctic oil reserves makes it important to obtain baseline pollutant measurements as soon as possible.

Transport of air pollutants into the Arctic has received much attention recently, and it seems that the Arctic haze north of Barrow, first reported in 1956, is due to large-scale transport of polluted air masses. Aerosol samples from the Arctic show that the concentrations of trace elements associated with fossil fuel combustion reach a pronounced maximum in February-March (K.A. Rahn \& R.J.M. Caffrey Proc. WMO Symp. on Long-Range Transport of Pollutants, Sofia, 25, WMO no.538; 1979). During summer, aerosol concentrations are very low (H. Lannefors, J. Herntzenberg \& H.C. Hansson Tellus 34A, no.1; in the press). This extreme variation is explained by the formation of a cold highpressure centre over northern USSR and Siberia in winter, which forces the Atlantic westerlies northwards into the Barents Sea. This enhances the south to north advection associated with the low pressures in the Atlantic and the Norwegian Sea. In addition, pollutant transformation and deposition rates are very low in the cold and dark winter season. Polluted air masses from Europe and the USSR are transferred into the polar basin and across the North Pole towards northern Alaska and Canada. In summer, the circulation becomes more circumpolar, and dry deposition and

\section{retic} from B. Ottar

precipitation prevent anthropogenic aerosols from reaching the high Arctic.

The new study includes an expansion of the present Norwegian measurement programme. Four ground stations in the high Arctic (Bear Island, Hopen, Spitsbergen, Jan Mayen) and two stations along the Norwegian coast will operate over a three year period, starting summer 1982, together with two inland stations. At all stations sulphur dioxide, sulphate aerosol and precipitation will be monitored throughout the year. More extensive supplementary measurements, including high-volume sampling and chemical analysis of aerosols and hydrocarbons, will be made during a few 1-2 month periods each year. In the same periods, intensive aerosol measurements will be carried out by aircraft and the vertical and horizontal extent of the polluted air masses mapped. Soil samples as well as biological samples will be collected to evaluate the deposition and accumulation of trace elements and organic components. In particular, the accumulation of chlorinated hydrocarbons, whose presence in the Arctic air has been demonstrated, will be examined in fish from isolated lakes.

Turbulent dispersion over ocean surfaces will also be studied in order to provide a better basis for calculation of hazard zones in connection with blowouts and other accidents. Such studies and the background air pollution inventory will help the Norwegian Government evaluate possible damage from Arctic oil activities.

B. Ottar is Director of the Norwegian Institute for Air Research, PO Box 130, 2001 Lillestrom. 